\title{
Physico-mechanical Characteristics of High Density Briquettes produced from Composite Sawdust
}

\author{
${ }^{* 1}$ BELLO, R S; ${ }^{2}$ ONILUDE, M A \\ ${ }^{I}$ Department of Agricultural \& Bio-Environmental Engineering Technology, Federal College of Agriculture, Ishiagu, Nigeria \\ ${ }^{2}$ Department of Wood Products Engineering, University of Ibadan, Nigeria \\ *Correspondent E-mail: segemi2002@gmail.com,Tel: 08068576763
}

\begin{abstract}
Physico-mechanical characteristics of briquettes produced from composite sawdust admixture using a screw press briquetting machine was investigated. Sample feedstock materials collected has particle sizes varying between $6-8 \mathrm{~mm}$ with $10-20 \%$ powdery components $(<4$ mesh). Briquette's physical characteristics investigated using standard test apparatus and procedures include dimensional stability immediately, 1 hour and 30 days after production, effects of particle moisture and particle size on briquette compressed and relaxed densities. Mechanical characteristics include resistance to gravity and impact, effects of densities on impact resistance index (IRI) and effects of briquette durability in water. Statistical models were used to establish empirical relationships between the feedstock materials (independent variables) and briquette characteristics (independent variables). The physical characteristics of briquettes produced at $12 \%$ are loose and brittle with poor dimensional stability, at $10 \%$ they are bonded but weak in strength with good dimensional stability while briquettes produced at $8 \%$ are wellformed, good colouration with char carbonation, excellent dimensional stability. The compressed density of the briquettes ranges of $490-820 \mathrm{~kg} / \mathrm{m}^{3}$. The lower moisture briquettes have high resistance to water dispersion, high impact resistance and excellent storability.
\end{abstract}

DOI: https://dx.doi.org/10.4314/jasem.v24i5.8

Copyright: Copyright (C) 2020 Bello and Onilude. This is an open access article distributed under the Creative Commons Attribution License (CCL), which permits unrestricted use, distribution, and reproduction in any medium, provided the original work is properly cited.

Dates: Received: 18 March 2020; Revised: 22 April 2020; Accepted: 14 April 2020

Keywords: Characterization, extrusion, briquette, sawmill, sawdust

Composite sawdust admixture are material wastes generated directly from primary and secondary wood processing machines without separation of its components into materials such as bark, dust, shaves, chips and other particulate matters. These materials are produced in large volumes from timber industries and they constitute nuisance to both public health and the environment when not properly managed (Elinwa and Abdulkadir, 2011). This has been affirmed by the increasing number of sawmills springing up in Nigeria today, particularly in the South west Nigeria (Bello and Onilude, 2013). The presence of these wastes in large quantity poses disposal problems for the industries. Taking advantage of the energy potentials wasted in burning of these massive wastes in open dump sites, their efficient use to meet part of energy demand for heating and gas emissions reduction through conversion processes has become imperative. These wastes can be briquetted in various forms, either as pellets, or briquettes through low or high temperatures and pressure applications and be utilized as high-grade solid briquette fuels by improving the calorific value and ensuring a clean smoke-free flame suitable for small scale industrial and domestic applications. A number of locally available materials have been briquetted for energy production according to (Faborode, 1988; Adekoya 1989; Ajayi and Lawal 1995; Olorunnisola 1998, 1999). Several research efforts have equally been extensively made to study compression characteristics of different types of biomass. For instance, alfalfa (Adapa et al., 2006; Hall and Hall 1968), straws/grasses (Demirbaş 1999; Kaliyan and Morey 2006; Mani et al., 2006a; Mani et al., 2006b; Ndiema et al., 2002; Shaw et al., 2006; Wamukonya and Jenkins 1995), palm fiber/shell (Husain et al. 2002), olive cake/refuse (Yaman et al., 2000), wood and wood waste (Chin and Siddiqui 2000; Li and Liu 2000) as well as sawdust/charred palm kernel shell (Kuti, 2009) among other studies. However, in many of the foregoing studies, the briquettes were produced as low/medium density, mostly with the aid of binders such as cassava starch and palm oil sludge which tend to produce smoky briquettes. This work presents studies on the physicomechanical characteristics of briquettes produced in binderless high temperature operation using composite sawdust from mill sites in the south-western Nigeria. In order to achieve this research objective, a screw press extruder developed at the University of Ibadan, Nigeria was used to produce the briquettes. 


\section{MATERIALS AND METHOD}

Experimental machine setup: The experimental machine (figure 1) used in this test was an electrically powered screw type extruder developed at the University of Ibadan, Nigeria. The machine is in four segments; the power unit, the speed reducer gear assembly, extrusion assembly and the control panel. The power unit comprising of an induction motor and a three-grooved belt-pulley power transmission system. The motor is mounted on an adjustable base joined to the main frame. The speed reducer gear assembly which serves dual functions of speed reducer and steady power transmission to the extruder. The extrusion assembly comprising of the extrusion barrel, the screw shaft, the die and heater. The barrel is mounted on the main frame with bolts while the screw shaft is supported (cantilever support) by a large double roller thrust bearing fitly fixed into the extruder barrel. The screw shaft is connected to the reducer gear output shaft through a detachable universal joint. The die comprises of a ring bracket attaching it to the barrel, the bored conical extrusion chamber that necked into a cylindrical bore which produces the final briquette.

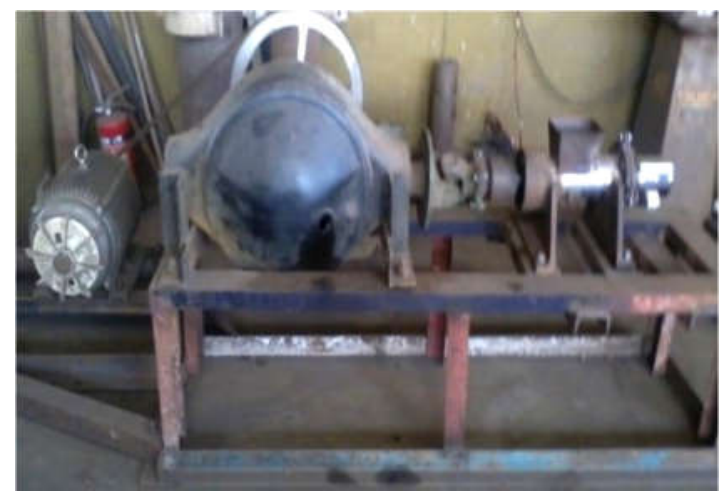

Fig 1: Experimental machine

Feedstock material preparation: Sawdust from sawn wood of different species (Figure 2) were collected from sawmill industries around Ibadan metropolis, sun dried to three moisture contents of $8 \%, 10 \%$ and $12 \%$. The feedstock material is composed of different particle sizes which are known to improve the packing dynamics and also contribute to high static strength (Ludwig, 1994). However, it is also desirable to have a randomly distributed particle sizes so that an adequate amount of sufficiently small particles is present for embedding into the larger particles. The materials were subjected to particle size analysis following ASAE Standard S319.4 test procedure according to Adapa et al, (2009) to determine its physical characteristics. These materials were sorted for foreign materials and other particulate matters and stored at room temperature conditions in readiness for briquetting.
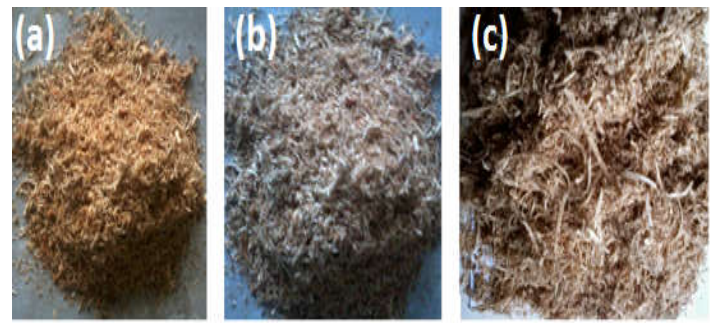

Fig 2: Sample feedstocks showing variations in particle sizes; a) 2$5 \mathrm{~mm}, 3-6 \mathrm{~mm}$ and $8-10 \mathrm{~mm}$

Methodology: The experimental machine at start-up was allowed to run at idle speed for five minutes to check for irregularities. Before the commencement of production, the heating elements was energized and subsequent die heating. The estimated start-up time for die heating was 15 minutes to allow enough time for the heaters to raise the temperature of the die to briquetting temperature of about $300^{\circ} \mathrm{C}$. The extruder induction motor is then powered and feedstocks loading commenced. The die heater element was set at a temperature of $270{ }^{\circ} \mathrm{C}$ and allowed to beat the die gradually to briquetting operating temperature of 300 ${ }^{\circ} \mathrm{C}$ over a period of $10-15$ minutes. The machine was then loaded with feedstock material intermittently with sawdust. From the point of loading to the time densified briquettes appeared from the die-end was regarded as the start-up time and progressively, the length of extrusion at intervals were measured until the machine stopped or the briquette break off.

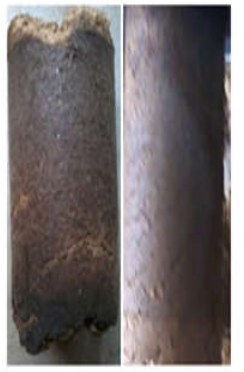

Sample $18 \%$ MC

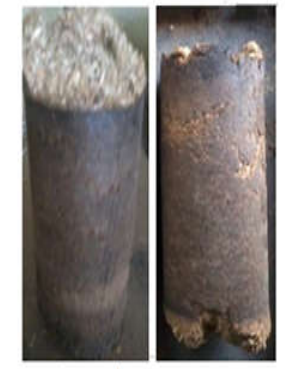

Sample $2(10 \% \mathrm{MC}) \quad$ Sample $3(12 \% \mathrm{MC})$
Fig 3: Briquette samples produced

Briquette performance test characteristics: The following physical characteristics were determined for sample briquettes produced.

Briquette physical characteristics: Briquette dimensional characteristics: The dimensional properties (diameter and unit lengths) of briquettes produced were consistently measured by a Vernier caliper at extrusion determine briquette stability and their durability tested according to test standards 
(Yogesh, 2016). Briquettes were tested for dimensional stability, immediately, 1 hour and 30 days after production. The percentage elongation in length, or relaxation in length, is expressed as

$$
\% \text { elongation }=\frac{L_{1}}{L_{2}-L_{3}} \quad 1
$$

Where; $\mathrm{L}_{1}=$ Total average elongation of samples along axial dimensions; $\mathrm{L}_{2}=$ Longest elongation measured moments after extrusion; $\mathrm{L}_{3}=$ Longest elongation measured after 1 hour

Dimensional stability of the products was tested immediately after the briquettes were produced and an hour after the product has fully been cooled (Figure 4).

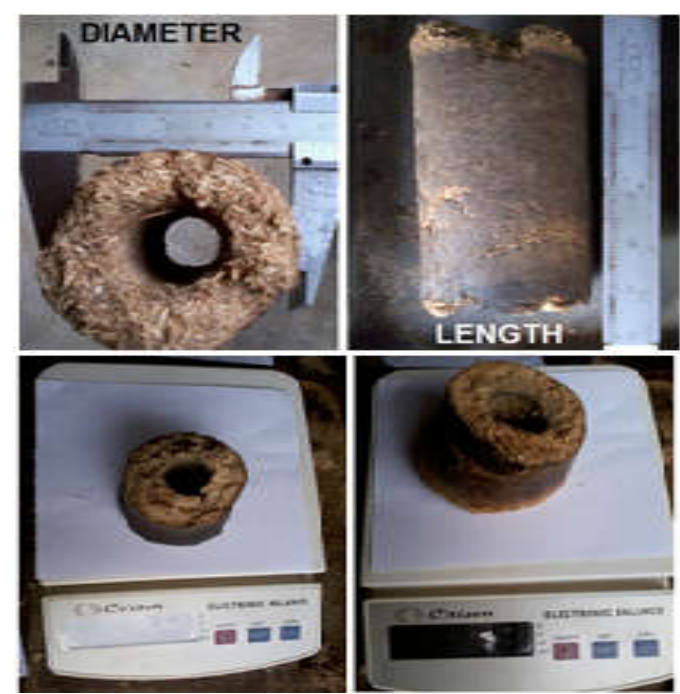

Fig 4: Measuring sample briquettes for dimensional stability and weight

Weight measurement: Samples of carefully cut briquettes were dressed and measured on electronic weighing balance as shown in figure 4 while the representative weights of samples were recorded.

Mechanical characteristics: Toughness test: The toughness of the briquettes defined through resistance to gravity drop was evaluated through the percentage of decrease in mass after dropping the briquettes at least three times from a height of $2.0 \mathrm{~m}$ on to a cemented concrete platform. After each drop, the test piece was put through a sieve with openings smaller than the minimum dimension of the briquette. According to Borowski, (2010), the gravitational resistance to drop should attain a value higher than $90 \%$. Briquette resistance to gravity is evaluated in the equation 5 below:

$$
K=\frac{B_{z}}{B} x 100
$$

Where: $\mathrm{B}=$ Briquette mass before dropping, $\mathrm{B}_{\mathrm{z}}=$ Mass remaining in filled sieve

Briquette densities: Briquette density measured immediately after production are regarded as compressed density, while briquette densities determined 30 days after removal from the press in accordance with ISO 3131 (1975) is regarded as relaxed density (RD). The briquette compressed density was calculated by dividing the average mass of the briquette by its volume.

$$
C D=\frac{\text { Mass }}{\text { Volume }}\left(\mathrm{g} \mid \mathrm{cm}^{3}\right)
$$

The mass of briquettes was determined using a laboratory electronic balance with an accuracy of 0.01 g. The diameter and length of a briquette were measured at three points with a Vernier Caliper. Relaxed density was then computed adopting the relation used by Mitchual et al., (2013):

$$
R D\left(g \mid \mathrm{cm}^{3}\right)=\frac{108,000 \times M(g)}{\pi\left[d_{1} m m+d_{2} m m+d_{3}\right]^{2} x\left[l_{1} m m+l_{2} m m+l_{3} m m\right]} \quad 4
$$

Where $\mathrm{d}_{1}, \mathrm{~d}_{2}$ and $\mathrm{d}_{3}$ are diameters $(\mathrm{mm})$ measured at three different points on the briquettes and $l_{1}, l_{2}$ and $l_{3}$ are lengths $(\mathrm{mm})$ measured at three different points on the briquettes. $\mathrm{M}(\mathrm{g})$ is the mass of briquette.

Compression test: Compressive strength is a criterion for determining briquette durability from the point of view of briquettes transportation, manipulation and storage. Briquettes' strength in cleft and axial pressure are two methods employed in compression tests. Since the briquettes shape is cylindrical, the compressive strength was determined in cleft failure for compressed and intact briquettes using an Instron universal testing machine in accordance to ASTM D 2166-85 (Adapa et al., 2006 and Mani et al., 2006b).

\section{RESULTS AND DISCUSSIONS}

Material particle distribution: The characteristics of sawdust particle sizes of sawdust produces by different sawing machines used in primary and secondary sawmill activities had been investigated by Bello (2017). Preliminary studies on sawdust samples collected showed that geometric mean particle size of feedstock particle varies between 6-8 mm with 10$20 \%$ (ASAE Standard S319.4) powdery component (< 4 mesh) which is known to give better products. It is also desirable to have a randomly distributed particle sizes so that an adequate amount of sufficiently small particles is present for embedding into the larger particles. 
Physical characteristics of samples: The representative weight, extrusion diameter, length and other physical attributes of samples measured after extrusion. Average dimensional changes along the diametric and length axes are $0.23 \mathrm{~mm}$ and $0.35 \mathrm{~mm}$ respectively (Table 1). This could be as a result of higher axial compression in the direction of forward movement resulting from screw conveyor. This condition could be explained by inter-particle interactions during densification.

Table 1: Dimensional stability of briquette samples

\begin{tabular}{lllllll}
\hline $\begin{array}{l}\text { Product } \\
\text { sample }\end{array}$ & $\begin{array}{l}\text { Dimensions } \\
\text { Diameter } \\
\text { moments (mm) }\end{array}$ & $\begin{array}{l}\text { Diameter 1hr } \\
\text { later }(\mathbf{m m})\end{array}$ & $\begin{array}{l}\text { Elongation } \\
(\mathbf{m m})\end{array}$ & $\begin{array}{l}\text { Dimensions } \\
\text { Length } \\
\text { moments (mm) }\end{array}$ & $\begin{array}{l}\text { Length 1 hr } \\
\text { later (mm) }\end{array}$ & $\begin{array}{l}\text { Elongation } \\
(\mathbf{m m})\end{array}$ \\
\hline 1 & 50.1 & 50.3 & 0.2 & 160.0 & 160.0 & 0 \\
2 & 50.0 & 50.2 & 0.2 & 200 & 200.2 & 0.2 \\
3 & 50.0 & 50.3 & 0.3 & 140.5 & 141.3 & 0.8 \\
4 & 50.2 & 50.2 & 0.2 & 120.7 & 121.1 & 0.4 \\
Average & 50.075 & 50.25 & 0.23 & 155.3 & 155.65 & 0.35 \\
\% diametric elongation & & $\mathbf{0 . 7 7}$ & \% lengthwise elongation & $\mathbf{0 . 4 5}$ \\
\hline
\end{tabular}

Briquettes dimensional changes in storage: A plot of dimensional changes in briquette samples at different moistures at extrusion, 1 hour and after 30 days in storage is shown in Figure 5. At higher moisture contents, the briquette experiences significant changes in dimension between extrusion time and 1 hour of production than after 30-days of storage, after which there are no significant changes in the product. This is largely explained by the moisture reduction over a period of time (30 days).

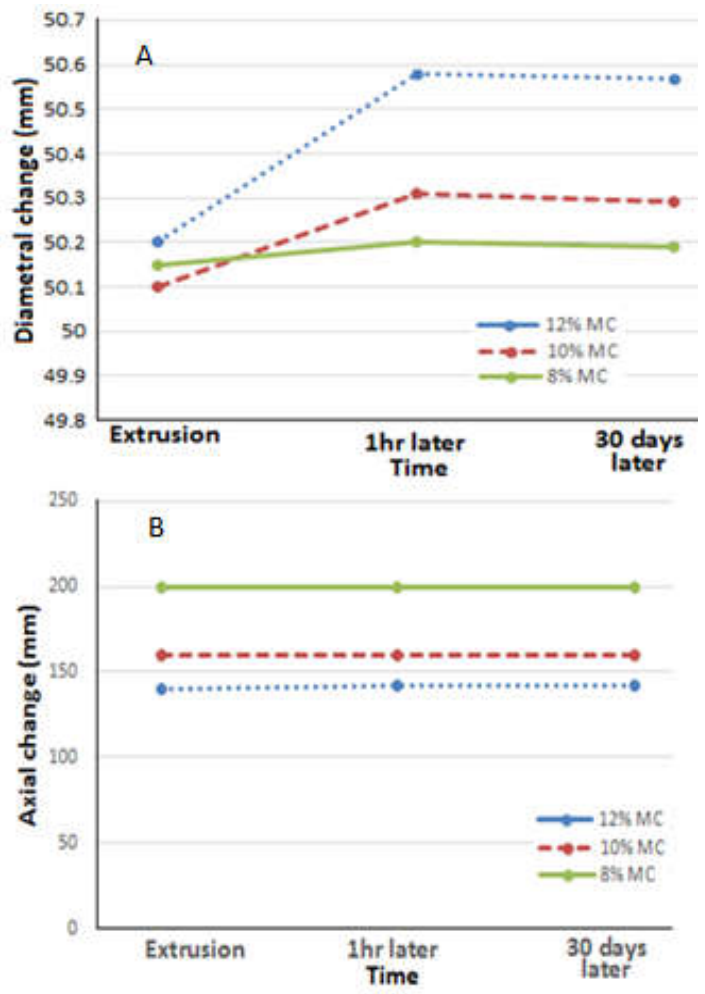

Fig 5: Diametral (A) and axial (B) changes of sample at different moisture contents

These characteristics indicates that briquettes are more dimensionally stable when produced at lower moistures than higher moistures. However, there are no significant changes in axial dimension in the briquettes at different moisture contents. This is explained by the lateral pressure applied in the direction of travel of the extruder and the inter-particle orientation in the direction of travel.

Effect of particle moisture on briquette compressed and relaxed densities: Figure 6 shows the effects of particle moisture on compressed and relaxed densities. At higher particle moisture contents, the compressed and relaxed densities increase up to $20 \%$ and $30 \%$ respectively while the densities are not significantly affected at lower moisture contents.

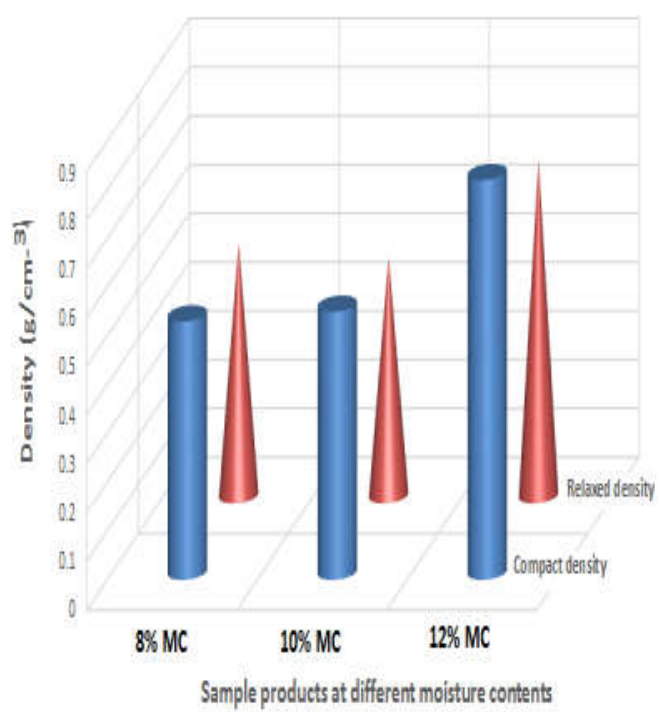

Fig 6: Compressed and relaxed densities at different moisture contents

A plot of multiple regression analysis using three models (linear, quadratic and exponential relations) to produce a curve of best fit between density and moisture contents was produced to validate this result. Among the three models, exponential multiple 
regression analysis provided a best fit curve (Figure 7) with the following regression equation predicting the compressed (CD) and relaxed (RD) density at any given particle moisture and size:

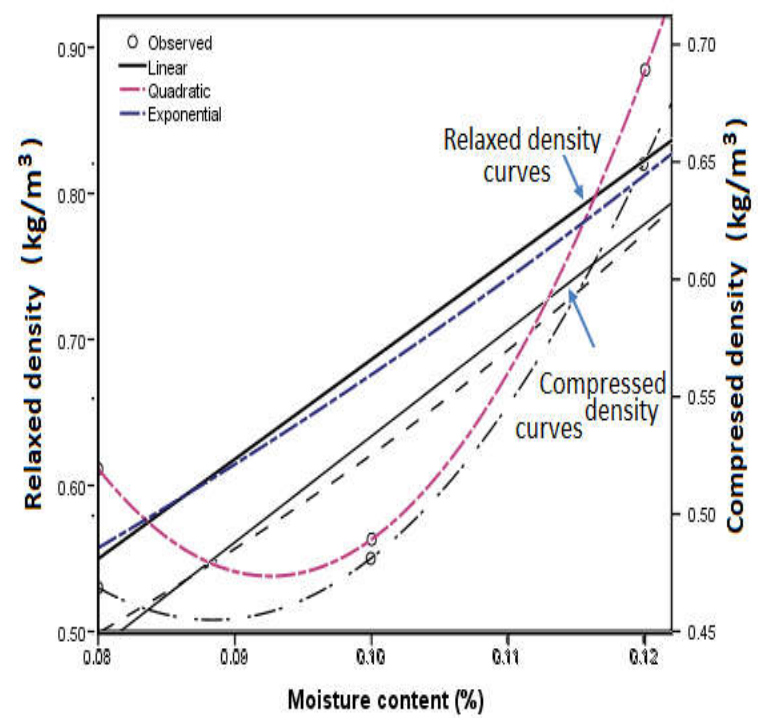

Fig 7: Regression relationship between densities and moisture contents

$$
\begin{array}{ll}
C D=0.2084 e^{10.912 M C} & 5 \\
R D=0.2762 e^{7.7016 M C} & 6
\end{array}
$$

These results suggest that the briquettes relaxed density increases with increasing compacting moisture level and that briquettes with lower moisture content are likely to have higher relaxed density than those with higher moisture content. A correlation analysis indicates a strong significant positive correlation between the Pearson's variables:

$$
\begin{gathered}
\text { RD: } r=0.902, r^{2}=0.913, \text { adjusted } r^{2}=0.626 \text { and } \\
\text { CD: } r=0.773, r^{2}=0.598, \text { adjusted } r^{2}=0.196 \text {. }
\end{gathered}
$$

It could be concluded that particle moisture content significantly increases the compressed density and reduces the relaxed density and consequently the quality for all briquettes

Effect of particle size on briquette compressed and relaxed densities: Briquette density increases with increase in proportion of smaller particles. Very fine particles have low void spaces and as such have low compressibility while coarse particle sizes have more tendencies of causing fissures that could cause cracks and fractures in compacted materials (MacBain, 1966). The finer the grind, the higher the quality of compact under low and medium density briquetting. At high particle moisture, fine particles materials merely grind and foul without binding while the coarse materials pulped. Fine particles readily absorb moisture than large particles, and therefore undergo a higher degree of grinding. Under high density briquetting, particle size has no significant impact on briquette quality because of high compacting pressure and simultaneous application of heat which melts the lignin to bind up the material particles. A correlation analysis between the relaxed density and particle size on one hand and compressed density and particle size on the other indicates a significant positive Pearson's correlation.

$$
\begin{gathered}
\text { RD: } r=0.576, \mathrm{r}^{2}=0.332 \text {, adjusted } \mathrm{r}^{2}=-0.337 \text { and } \\
\text { CD: } \left.\mathrm{r}=0.754, \mathrm{r}^{2}=0.568 \text {, adjusted } \mathrm{r}^{2}=0.136\right) \\
\text { respectively. }
\end{gathered}
$$

These results suggest that the material particle size has an exponential relationship with relaxed and compressed densities of the briquettes produced. An exponential multiple regression analysis provided a best fit curve (Figure 8) with the following exponential regression equation predicting the density at any given particle moisture and size:

$$
\begin{array}{ll}
C D=0.380 e^{0.064 P S} & 7 \\
R D=0.422 e^{0.037 P S} & 8
\end{array}
$$

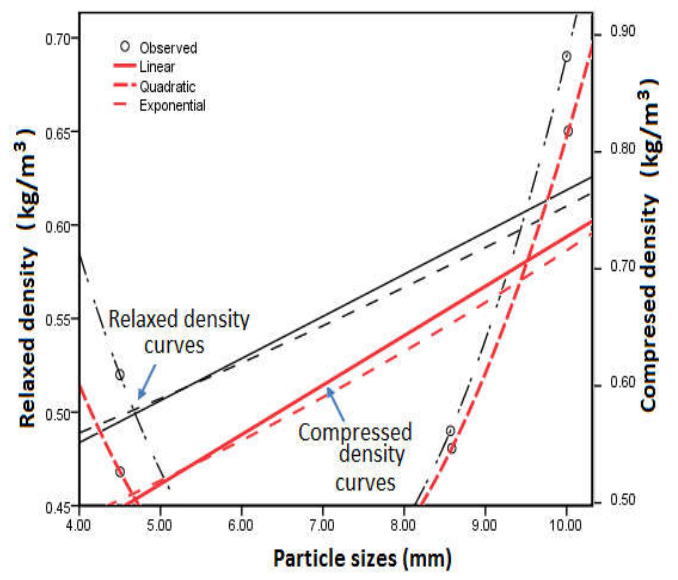

Fig 8: Regression curves for relationship between densities and particle size

Multiple effects of particle sizes and moisture content on densities: To establish the relative contributions of independent variables; moisture content and particle size in predicting the compressed and relaxed densities of briquettes and to establish the mathematical relationship between them, a partial multiple regression analysis was carried out using three models; linear, quadratic and exponential. A correlation analysis between dependent relaxed and compressed densities and independent particle moisture and particle size indicates strong significant positive correlations between moisture and particle size and 
weak positive correlations between relaxed density and particle size respectively (Pearson's $r=0.788, \mathrm{p}$ value $=0.000 ; \mathrm{N}=3$; two-tailed, $\alpha=0.442$ and Pearson's $\mathrm{r}=0.915, \mathrm{p}$ value $=0.000 ; \mathrm{N}=3$; two-tailed, $\alpha=0.284)$. These results suggest that the relaxed density of the briquettes increases with increasing particle size and that briquettes produced from smaller particle size sawdust are likely to have higher relaxed density than those with larger particle size. Compressed density was also found to have a very strong Pearson's correlation and weak positive nonsignificant correlation with the relaxed density of the briquettes (Pearson's $\mathrm{r}=0.980, \mathrm{p}$ value $=0.000 ; \mathrm{N}=$ 3; 2-tailed, $\alpha=0.128)$.

Effect of moisture content and material particle sizes on compressed and relaxed densities: ANOVA of the effect of moisture content and material particle size on compressed and relaxed densities outcomes in Tables 2 and 3 shows that at 5\% level of significance and their interactions, particle size have more significant effects on the relaxed density than the compressed density of briquettes produced.

Table 2: ANOVA of effects of material properties on relaxed density

\begin{tabular}{llclll}
\hline Source & $\begin{array}{l}\text { Sum of } \\
\text { squares }\end{array}$ & Df & $\begin{array}{l}\text { Mean } \\
\text { square }\end{array}$ & f & Sig. \\
\cline { 2 - 2 } & 0.014 & 1 & 0.014 & 1.639 & 0.422 \\
Residual & 0.009 & 1 & 0.009 & & \\
Total & 0.023 & 2 & & & \\
PS & 0.008 & 1 & 0.008 & 0.548 & 0.594 \\
Residual & 0.015 & 1 & 0.015 & & \\
Total & 0.023 & 2 & & & \\
\hline
\end{tabular}

Table 3: ANOVA of effects of material properties on compressed

\begin{tabular}{llllll}
\hline Source & $\begin{array}{l}\text { Sum of } \\
\text { squares }\end{array}$ & Df & $\begin{array}{l}\text { Mean } \\
\text { square }\end{array}$ & F & Sig. \\
\cline { 2 - 2 } & 0.042 & 1 & 0.042 & 4.037 & 0.294 \\
Residual & 0.010 & 1 & 0.010 & & \\
Total & 0.052 & 2 & & & \\
PS & 0.029 & 1 & 0.029 & 1.238 & 0.466 \\
Residual & 0.023 & 1 & 0.023 & & \\
Total & 0.052 & 2 & & & \\
\hline
\end{tabular}

The multiple coefficient of determination, R-value and the root mean square error for the ANOVA model were 0.9907 and 11.24 , respectively. Thus, it could be deduced that particle size and moisture content, and their interactions explained about $99.07 \%$ of the variability in the relaxed density of the briquettes produced. Table 4 shows the unstandardized $(\beta)$ and standardized (Beta) regression coefficients, the multiple correlation coefficient $(\mathrm{R})$, adjusted $\mathrm{R}^{2}$, the $\mathrm{t}$ value and its associated $\mathrm{p}$ value for each of the variables using a linear multiple regression analysis. From the table 4, particle size and moisture content collectively explained $70.9 \%$ (adjusted $\mathrm{R}^{2}=0.603$ and $0.106)$ of the variance in the compressed density of briquette produced and 5.0\% (adjusted $\mathrm{R}^{2}=0.242$ and -0.292 ) of the variance in the relaxed density respectively. This suggests that the linear regression model is a good predictor of compressed density for high density briquettes $\left(\mathrm{R}^{2}=0.709, \mathrm{p}\right.$ value $\left.=0.000\right)$ and poor predictor of relaxed density. Based on the Beta values, it could be inferred that the mathematical relationships between the dependent variables; compressed and relaxed density and the independent variables, moisture content $(M C)$, and particle size (PS) are presented in equations 9 and 10 .

Table 4: Regression analysis of moisture content and particle size on densities

\begin{tabular}{llcccccc}
\hline Variables & B & Beta & R & $\begin{array}{l}\text { R } \\
\text { square }\end{array}$ & $\begin{array}{l}\text { Adjusted } \\
\mathbf{R}\end{array}$ & T & p value \\
\hline $\begin{array}{l}\text { Compressed density } \\
\text { Moisture content }\end{array}$ & 7.250 & & & & & & \\
$\begin{array}{l}\text { Constant } \\
\text { Particle size }\end{array}$ & -0.092 & 0.895 & 0.895 & 0.801 & 0.603 & -0.251 & 0.102 \\
$\begin{array}{l}\text { Constant } \\
\text { Relaxed density }\end{array}$ & 0.042 & 0.309 & 0.744 & 0.744 & 0.553 & 0.106 & 1.113 \\
$\begin{array}{l}\text { Moisture content } \\
\text { Constant }\end{array}$ & 4.250 & 0.788 & 0.788 & 0.621 & 0.242 & 1.013 \\
$\begin{array}{l}\text { Particle size } \\
\text { Constant }\end{array}$ & 0.142 & & & & & 0.421 \\
\hline
\end{tabular}

Compressed density $\left(\mathrm{kg}_{3} \mathrm{~m}^{3}\right)=0.309+7.250 \mathrm{MC}+0.042$ PS 9

Relaxed density $\mathrm{kg} / \mathrm{m}^{3}=0.394+4.250 \mathrm{MC}+0.022 \mathrm{PS} \quad 10$ 
Mechanical characteristics: Briquette toughness: After repeatedly dropping each sample of the briquettes from a 2-m height to the laboratory concrete floor, the percentage of weight loss ratio between the loss in weight and the total weight was determined as shown in Table 5. From the tests conducted, after the repeated number of drops, observations revealed that all the briquettes studied did not shatter into pieces. From literatures, the gravitational resistance to drop should attained a maximum value of $93.09 \%$ and a minimum value of $89.55 \%$ which is in agreement with Borowski, (2010) that gravitational resistance to drop should attain a value higher than $90 \%$.

Table 5: Briquette resistance to gravity and impact at 2-m drop height

\begin{tabular}{llllll}
\hline Samples & $\begin{array}{l}\text { Sample } \\
\text { weights (g) }\end{array}$ & $\begin{array}{l}\text { Final wt. after } \\
\text { 5 drops (g) }\end{array}$ & $\begin{array}{l}\text { Weight } \\
\text { loss (g) }\end{array}$ & $\begin{array}{l}\text { \% wt. } \\
\text { loss }\end{array}$ & $\begin{array}{l}\text { Toughness } \\
(\mathbf{1 0 0 \% )}\end{array}$ \\
\hline Light brown (1) & 155 & 144.29 & 10.71 & 8.62 & 93.09 \\
Char (black) (2) & 206 & 188.03 & 17.97 & 8.72 & 91.28 \\
Deep brown (3) & 227 & 205.60 & 21.4 & 9.42 & 90.57 \\
Deep brown (4) & 101 & 90.45 & 10.55 & 10.45 & 89.56 \\
\hline
\end{tabular}

Effect of densities on impact resistance index (IRI): The relationships between impact resistance index, compressed and relaxed densities for the treatments at $8 \%$ moisture ratio plotted on partial regression charts (Figure 9) on the two densities.

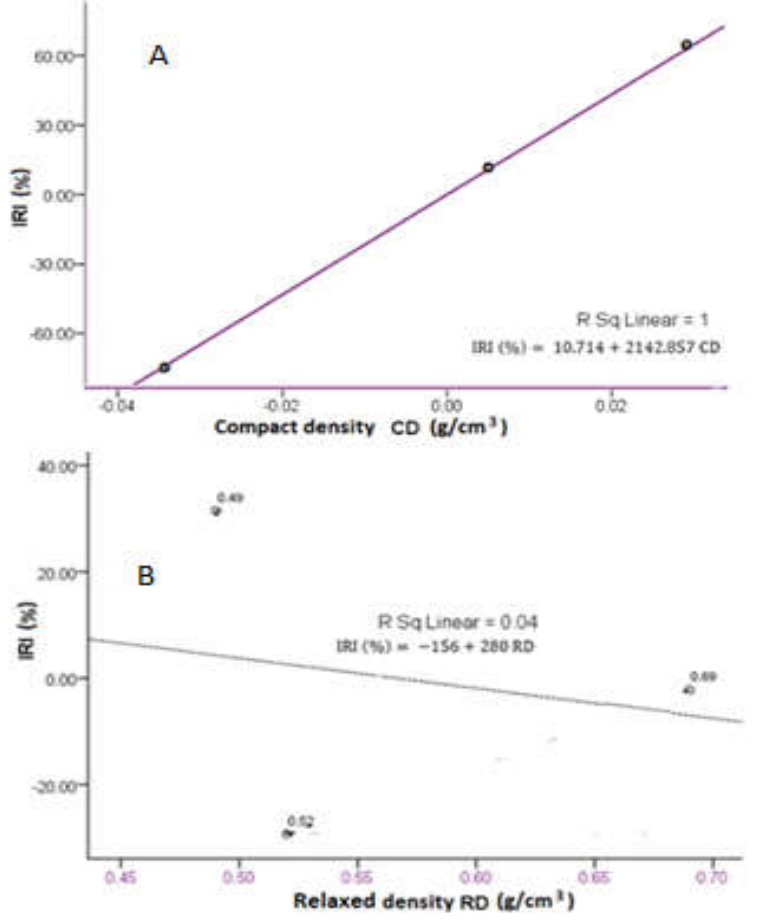

Fig 9: Partial regression curve for IRI briquette compressed density (a) and relaxed density (b)
The mathematical relationships obtained between impact resistance index, compressed and relaxed density are presented in the following expressions:

Compressed density:

$$
\operatorname{IRI}(\%)=10.714+2142.857 \mathrm{CD}
$$

Relaxed density:

$$
\operatorname{IRI}(\%)=-156.00+280.00 \mathrm{RD}
$$

Owing to the weak nature of briquettes formed at $10 \%$ and $12 \%$ particle moistures, durability tests performed on them show high degree of shattering.

Effect of moisture content and particle size on impact resistance index (IRI): A multiple linear regression analysis was carried out to establish the relative contributions of independent variables; moisture content and particle size in predicting impact resistance of briquettes, and to establish the mathematical relationship between them (Table 6). The results indicate that at 5\% level of significance and $95 \%$ confidence interval for $\beta$, the impact resistance index of briquettes were significantly affected by moisture and particle sizes. The mathematical relationship between impact resistance index, compressed and relaxed density is presented in Equation (13):

$$
I R I \%=650.137-1412.967 R D+2161.050 C D
$$

\begin{tabular}{|c|c|c|c|c|c|c|c|}
\hline Variables & $\mathrm{B}$ & Beta & $\mathbf{R}$ & R Square & Adjusted R ${ }^{2}$ & & $p$ value \\
\hline Constant & 650.137 & & & & & & \\
\hline RD* & -1412.967 & -.751 & 1.000 & 1.000 & 0.0 & - & - \\
\hline CD* & 2161.050 & 1.724 & & & & & \\
\hline
\end{tabular}

Table 6: Regression analysis of IRI on briquette' densities 
Effect of water on briquette durability in water: The onset dispersion time for each briquette when immersed was observed. The results indicate water resistance capacity of the briquettes varied from $25 \pm$ $1.65 \%$ (B12) to $61 \pm 3.12 \%$ (B10) to $94.21 \pm 3.76 \%$ (B8) for the three studied moisture levels. It was observed that the briquette produced at $12 \%$ ) had good hygroscopic properties as compared to the briquettes from the lower moisture levels. The briquette from $8 \%$ moisture level exhibits the least water absorption characteristics. This is an indication that hygroscopic property of briquettes at different moisture levels showed a linear relationship between water absorption capacity and moisture content.

Conclusions: Based on the physico-mechanical characteristics of briquettes produced, we conclude that, feedstock particle sizes and moisture content contributes to the quality of briquette. Sound briquettes with better physical attributes are produced at lower particle moisture contents. Particle size has no significant impact on briquette physical quality because of high compacting pressure and simultaneous application of heat which melts the lignin to bind up the material particles. Briquettes percentage elongations are significantly low along the diametral axial axes; but higher along the diametrical axis. High particle moisture significantly increases the compressed density and reduces the relaxed density and consequently the briquettes quality. The briquettes relaxed density increases with increasing particle size. The impact resistance index (IRI) of briquettes was significantly affected by moisture and particle sizes. Durability tests on $10 \%$ and $12 \%$ particle moisture briquettes show high degree of shattering. Briquette produced at $12 \%$ had good hygroscopic properties compared to those from lower moisture levels. Lower moisture briquettes exhibit the least water absorption characteristics, indicating hygroscopic property of briquettes and the linear relationship between water absorption capacity and moisture content.

\section{REFERENCES}

Adekoya LO, (1989). Investigation into the briquetting of sawdust. The Nigerian Engineer 4(3):1-10.

Ajayi OA; Lawal CT, (1995). Some quality indicators of sawdust/palm oil sludge briquettes. J. Agric. Eng. Technol. 30: 55-65.

Adapa, PK Singh A; Schoenau GJ; Tabil LG, (2006). Pelleting characteristics of fractionated alfalfa grinds - hardness models. Inter. J. Powder Handling and Processing. 18(5), 294-299
Adapa, P; Tabil LG; Schoenau G, (2009). Compression Characteristics of Selected Ground Agricultural Biomass. Agric. Eng. Inter. Ejournal. XI

Bello RS, (2017). Characterization of sawdust produced from circular, chain and band sawing machines, Bioprocess Eng. 1: (1) 21-29

Bello RS; Onilude MA (2013). Sawmill wastes briquetting and its potentials in the minimization of greenhouse gas (GHG) emissions. In Sustainable Environmental Management: Issues \& Projections. Eds Bello R. S. Balogun R. B. \& Okereke S. N. ch 19. 241-264. Createspace, Charl US. ISBN-13: 978-149-285-349-7 https://www.createspace.com/4462554

Borowski G, (2010). Possibilities of utilization of energy briquettes. Lublin University of Technology 20-618 Lublin, Nadbystrzycka 38, Poland. Date modified $28^{\text {th }}$ May, 2010

Chin OC; Siddiqui KM, (2000). Characteristics of Some Biomass Briquettes Prepared Under Modest Die Pressures. Biomass and Bioenergy. $18,223-228$.

Demirbas A, (1999). Physical properties of briquettes from waste paper and wheat straw mixtures. Energy Conversion and Management 40, 437445

Elinwa AU; Abdulkadir S, (2011). Characterizing Sawdust-ash for Use as an Inhibitor for Reinforcement Corrosion - Elinwa, Abdulkadir 2011

http://citeseerx.ist.psu.edu/showciting? cid $=1958$ 7041

Faborode MO, (1988). Briquetting waste hyacinth for domestic and rural agro- industrial fuel application. The Proceedings of the International. Workshop/Seminar on Water Hyacinth; 1988 Aug 7-12; Lagos,. Nigeria. Federal Ministry of Science and Technology.

Hall GE; Hall CW, (1968). Heated-die wafer formation of alfalfa and Bermuda grass. Transactions of the ASAE 11:578-581.

ISO (1975): Standard test method for density of regular solids. International standard ISO 3131: Geneva: ISO; 
Kaliyan N; Morey RV, (2008). Factors Affecting Strength and Durability of Densified Biomass Products. Biomass and Bioenergy, 1- 23.

Kuti OA, (2009). Performance of Composite Sawdust Briquette Fuel in a Biomass Stove under Simulated Condition. Technical Report AU J.T. 12(4): 284-288.

Ludwig C, (1994). How and why solids agglomerate, Chemical Engineering, 156-160, Jan'94.

Li Y; Liu H, (2000). High pressure densification of wood residues to form an upgraded fuel. Biomass and Bioenergy, 19: 177-186.

Mani S.; Tabil, L.G.; Sokhansanj, S., (2006a). Effects of compressive force, particle size and moisture content on mechanical properties of biomass pellets from grasses. Biomass and Bioenergy 30, 648-654.

Mani S; Tabil LG; Sokhansanj S, (2006b). Effects of Compressive Force, Particle Size and Moisture Content on Mechanical Properties of Biomass Pellets from Grasses. Biomass and Bioenergy, 97, 1420-1426.

Mitchual SJ; Kwasi F; Nicholas AD, (2013). Effect of species, particle size and compacting pressure on relaxed density and compressive strength of fuel briquettes. Inter. J. Energy Environ Eng. 4: 30

Ndiema CWK; Manga PN; Ruttoh CR, (2002). Densification Characteristics of Rice Straw Briquettes. J. of the Institute of Energy. 75 (502) 11-13.
Olorunnisola AO, (1998). The performance of sawdust briquettes combusted in a conventional coal stove. Nig. J. Forestry 28(1):15 - 18.

Olorunnisola AO, (1999). The efficiency of two Nigerian cooking stoves in handling corncob briquettes. Nigerian J. Renewable Energy 7(1\&2): 31-34.

Shaw MD; Tabil LG; Panigrahi S; Chang P, (2006). Evaluation of compression, relaxation, and frictional properties of peat moss, wheat straw, oat hull, and flax shive grinds. Poster presented at the Third International Conference on Biomass for Energy, September 18-20, Kiev, Ukraine. fly (Mayetiola destructor (Say)). ASABE-CSBE Paper SD05-1004. St. Joseph, MI: ASAE.

Yaman S; Sahan M; Haykiri-acma H; Sesen K; Kucukbayrak S, (2000). Production of fuel briquettes from olive refuse and paper mill waste. Fuel Processing Technology 68:23-31.

Yogesh ST, (016). Studies on some engineering properties of rice straw based briquettes. $\mathrm{M}$. Tech. (Agril. Engg.) Thesis submitted to the Department of Farm Machinery and Power Engineering, Faculty of Agricultural Engineering, Indira Gandhi Krishi Vishwavidyalaya Raipur (Chhattisgarh)

Wamukonya L; Jenkins B, (1995). Durability and Relaxation of Sawdust and Wheat-Straw Briquettes as Possible Fuels for Kenya. Biomass and Bioenergy. 8 (3). 175-179. 